\title{
Elephant breakdown
}

\section{Social trauma: early disruption of attachment can affect the physiology, behaviour and culture of animals and humans over generations.}

\section{G. A. Bradshaw, Allan N. Schore, Janine L. Brown, Joyce H. Poole and Cynthia J. Moss}

$\mathrm{T}$ he air explodes with the sound of highpowered rifles and the startled infant watches his family fall to the ground, the image seared into his memory. He and other orphans are then transported to distant locales to start new lives. Ten years later, the teenaged orphans begin a killing rampage, leaving more than a hundred victims.

A scene describing post-traumatic stress disorder (PTSD) in Kosovo or Rwanda? The similarities are striking - but here, the teenagers are young elephants and the victims, rhinoceroses. In the past, animal studies have been used to make inferences about human behaviour. Now, studies of human PTSD can be instructive in understanding how violence also affects elephant culture.

Psychobiological trauma in humans is increasingly encountered as a legacy of war and socio-ecological disruptions. Trauma affects society directly through an individual's experience, and indirectly through social transmission and the collapse of traditional social structures. Long-term studies show that although many individuals survive, they may face a lifelong struggle with depression, suicide or behavioural dysfunctions. In addition, their children and families can exhibit similar symptoms, including domestic violence. Trauma can define a culture.

How PTSD manifests has long been a puzzle, but researchers today have a better idea as to why the effects of violence persist so long after the event. Studies on animals and human genocide survivors indicate that trauma early in life has lasting psychophysiological effects on brain and behaviour.

Under normal conditions, early motherinfant interactions facilitate the development of self-regulatory structures located in the corticolimbic region of the brain's right hemisphere. But with trauma, an enduring right-brain dysfunction can develop, creating a vulnerability to PTSD and a predisposition to violence in adulthood. Profound disruptions to the attachment bonding process, such as maternal separation, deprivation or trauma, can upset psychobiological and neurochemical regulation in the developing brain, leading to abnormal neurogenesis, synaptogenesis and neurochemical differentiation. The absence of compensatory social structures, such as older generations, can also impede recovery.

Elephant society in Africa has been

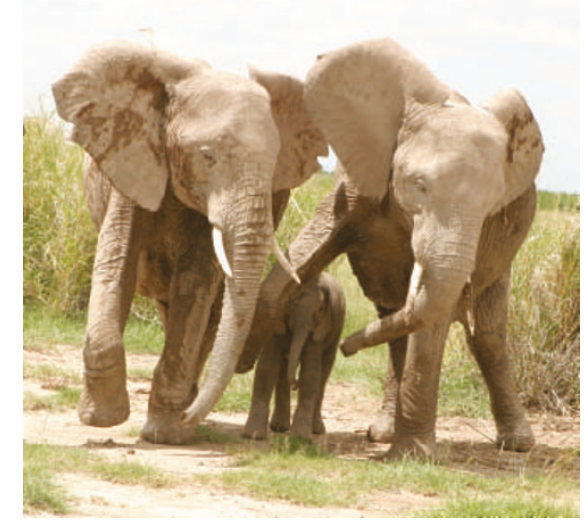

Social bonds guide an elephant's development.

decimated by mass deaths and social breakdown from poaching, culls and habitat loss. From an estimated ten million elephants in the early 1900s, there are only half a million left today. Wild elephants are displaying symptoms associated with human PTSD: abnormal startle response, depression, unpredictable asocial behaviour and hyperaggression.

Elephants are renowned for their close relationships. Young elephants are reared in a matriarchal society, embedded in complex layers of extended family. Culls and illegal poaching have fragmented these patterns of social attachment by eliminating the supportive stratum of the matriarch and older female caretakers (allomothers).

Calves witnessing culls and those raised by young, inexperienced mothers are highrisk candidates for later disorders, including an inability to regulate stress-reactive aggressive states. Even the fetuses of young pregnant females can be affected by prenatal stress during culls. The rhinoceroskilling males may have been particularly vulnerable to the effects of pre- and postnatal stress for two reasons. Studies on a variety of species indicate that male mammalian brains develop at a slower rate relative to females, but also that elephant males require a second distinct phase of socialization.

As with females, male socialization begins during infancy with the mother and a tight constellation of allomothers. But in adolescence, males leave the natal family to participate in older all-male groups, a period coincident with a second major stage of brain reorganization identified in humans. Cull orphans sustain a series of traumas, such as premature weaning, shock and the lack of older male socialization. The critical role of older males in normal social development was clearly demonstrated when researchers re-introduced older bulls to quell the young males' violence. Hyperaggression and abnormally early musth cycles (periods of sexual activity and hormonal shifts) both ceased.

Elephant hyperaggression is not an isolated event. At another heavily affected African park, intraspecific mortality among male elephants accounts for nearly $90 \%$ of all male deaths, compared with $6 \%$ in relatively unstressed communities. Elsewhere, including Asia, there are reports of poor mothering skills, infant rejection, increased 'problem animals' and elevated stress-hormone levels.

Elephant sociality is both a strength and a weakness. As with humans, an intact, functioning social order helps buffer trauma. But as human populations increase, more elephants are likely to live in environments characterized by severe anthropogenic disturbance. Current methods for conserving both wild and captive elephant populations fail to preserve elephant social systems. Even successful rehabilitation centres, such as The David Sheldrick Wildlife Trust, can only partially restore social processes because there are not enough older herd members. There is an added danger to social breakdown, namely that selection for asocial heritable traits in the absence of normal socialization may increase under adverse conditions. All these factors bring into question what kinds of behaviour are being promulgated in both exsitu and in situ conservation programmes, and compel new conservation strategies that promote normal social patterns.

Neuroscience has demonstrated that all mammals share a ubiquitous developmental attachment mechanism and a common stressregulating neurophysiology. Now, a wealth of human-animal studies and the experiences of human victims of violence are available to help elephants and other species survive. G. A. Bradshaw is at the Environmental Sciences Graduate Programme and the Department of Forest Science, Oregon State University, Oregon, USA. Allan N. Schore is in the Department of Psychiatry, University of California, Los Angeles, California, USA. Janine L. Brown is at the Smithsonian National Zoological Park, Washington DC, USA. Joyce H. Poole and Cynthia J. Moss are at the Amboseli Elephant Research Project (AERP), Nairobi, Kenya.

\section{FURTHER READING}

Clubb, R. \& Mason, G. A Review of the Welfare of Elephants in European Zoos (RSPCA, Horsham, 2002). Schore, A. N. Affect Dysregulation and Disorders of the Self (W. W. Norton, New York, 2003).

Slotow, R. et al. Nature 408, 425-426 (2000). 